Available online on 15.02.2019 at http://jddtonline.info
Journal of Drug Delivery and Therapeutics
Open Access to Pharmaceutical and Medical Research
$\begin{gathered}\text { (c)11-18, publisher and licensee JDDT, This is an Open Access article which permits unrestricted } \\ \text { non-commercial use, provided the original work is properly cited }\end{gathered}$

Open $\odot$ Access

Research Article

\title{
Prevalence of impaired renal function in patients of liver cirrhosis with or without spontaneous bacterial peritonitis
}

\author{
Dutta Siddhartha ${ }^{{ }^{*}}$, Chawla Shalini ${ }^{2}$, Srivastava Siddharth ${ }^{3}$, Loomba Poonam ${ }^{4}$, Roy Vandana ${ }^{5}$ \\ ${ }^{1}$ Resident, Department of Pharmacology, Maulana Azad Medical College, BZD Marg, New Delhi- 110002, India \\ ${ }^{2}$ Director Professor, Department of Pharmacology, Maulana Azad Medical College, New Delhi, India. \\ ${ }^{3}$ Associate Professor, Department of Gastroenterology, Govind Ballabh Pant Institute of Postgraduate Medical Education and Research, New \\ Delhi, India. \\ ${ }^{4}$ Director Professor, Department of Microbiology, Govind Ballabh Pant Institute of Postgraduate Medical Education and Research, New Delhi, \\ India. \\ ${ }^{5}$ Director Professor, Head of the Department, Department of Pharmacology, Maulana Azad Medical College, New Delhi, India
}

\begin{abstract}
Background: Renal Impairment (RI) is a common complication in patients with liver cirrhosis and ascites. Spontaneous Bacterial Peritonitis (SBP) a complication in cirrhosis further aggravates and worsens the scenario. Blood urea nitrogen (BUN)/creatinine ratio (BCR) is one of the common laboratory tests used to distinguish prerenal azotemia (PR) from acute tubular necrosis and proves to be handy in absence of other tests.

Objective: To find the prevalence of renal impairment in the patients of liver cirrhosis with or without SBP.

Design and Setting: Observational, prospective, single centre study.

Methods: Cirrhotic patients with SBP or low Ascitic fluid protein were enrolled. RI was considered if the serum creatinine or urea or both were above the reference range. BCR was obtained for each patient and divided based on BCR $<20$ and BCR $>20$. Assessment of variability of BCR values was done by further dividing them into eight subgroups $(<10,10-15,16-20,21-25,26-30,31-35,36-40$ and $>40)$.

Results: 34 patients were enrolled and divided into two groups. Group A with 22 patients with SBP and group B with 12 patients with low ascitic fluid protein. Group A had $77.27 \%$ patients with RI and group B had $58.33 \%$. Majority of the patients had BCR $>20$ group denoting a RI of PR type. Three patients had BCR $>40$ indicating towards a probable gastrointestinal haemorrhage.

Conclusion: This study gives an idea about the common occurrence of renal impairment in the patients of liver cirrhosis and ascites which needs early intervention to improve the prognosis.
\end{abstract}

Keywords: Renal Impairment; Renal failure; Blood urea nitrogen creatinine ratio; BCR Spontaneous Bacterial Peritonitis; Liver cirrhosis

Article Info: Received 05 Jan 2019; Review Completed 09 Feb 2019; $\quad$ Accepted 10 Feb 2019; Available online 15 Feb 2019

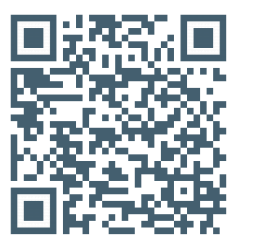

Cite this article as:

Dutta S, Chawla S, Srivastava S, Loomba P, Roy V, Prevalence of impaired renal function in patients of liver cirrhosis with or without spontaneous bacterial peritonitis, Journal of Drug Delivery and Therapeutics. 2019; 9(1-s):286-289 DOI: http://dx.doi.org/10.22270/jddt.v9i1-s.2349

*Address for Correspondence:

Dr. Siddhartha Dutta, Senior Resident, Department of Pharmacology, All India Institute of Medical Sciences (AIIMS), Jodhpur-342005, Rajasthan, India.

\section{INTRODUCTION}

Cirrhosis of liver is a late stage complication due to fibrosis of the liver which can be due to several liver diseases, most commonly due to hepatitis and chronic alcoholism. With each insult to the liver, it tries to repair itself and with continuous damage and repair, scar tissue forms. With propagation of liver damage, the scarring increases and leads to cirrhosis which turns out to be irreversible. ${ }^{1}$ Patients with cirrhosis are at a very high risk of developing various complications which ultimately leads to a decreased life expectancy. ${ }^{2}$ Cirrhosis in presence of its associated complications has turned out to be a leading cause of death in present scenario. The common complications associated with cirrhosis are esophageal or other varices, ascites, hepatic encephalopathy, portal hypertension, hepatocellular carcinoma, hepatorenal syndrome, spontaneous bacterial peritonitis, and coagulation disorders. ${ }^{3}$ Renal failure is a common complication in these patients and is associated with increased mortality and morbidity in patients with cirrhosis. ${ }^{4}$ Literature search has revealed that the prevalence of acute kidney injury(AKI) in hospitalized patients with cirrhosis is estimated to be approximately 20-50\%.4 Hepatorenal syndrome (HRS) is a type of (AKI) which occurs 
due to renal vasoconstriction and hypoperfusion as a result of extensive splanchnic vasodilatation. There is a strong evidence that HRS is also caused because of increased circulating proinflammatory cytokines like TNF-alpha and Interleukins. ${ }^{5}$ Hence, the present diagnostic criteria includes spontaneous bacterial peritonitis (SBP) as a trigger event in the development of HRS. ${ }^{6}$ The patients of cirrhosis with ascites with a previous episode of SBP or low ascitic albumin levels (less than $1.5 \mathrm{~g} / \mathrm{dL}$ ) are at significant higher risk of developing SBP.7,8 Thus, an early diagnosis and treatment of SBP plays a crucial role. ${ }^{8}$ AKI in cirrhosis worsens the prognosis of the patient so early diagnosis and intervention is of utmost importance for effective management and improved outcome. The renal impairment can be diagnosed by various criteria like RIFLE (Risk Injury Failure Loss Endstage renal disease) criteria and AKIN (Acute Kidney Injury Network) criteria. ${ }^{9}$

The novel classification system, AKI in cirrhosis is defined as an increase in serum creatinine of $0.3 \mathrm{mg} / \mathrm{dl}$ within $48 \mathrm{~h}$, or $50 \%$ or 1.5 -fold from baseline within 7 days. ${ }^{10}$ The International Club of Ascites (ICA) modified this new definition of AKI in cirrhosis, called ICA-AKI which was based on the percentage increase of serum creatinine from baseline and the peak value of serum creatinine during hospitalization.11,12 Early recognition of the cause of AKI, particularly differentiating prerenal azotemia (PRA) and acute tubular necrosis (ATN) is considered a critical clinical strategy because fluid resuscitation can improve PRA but can worsen ATN. ${ }^{13,14}$

The blood urea nitrogen (BUN)/creatinine ratio (BCR) is one of the common laboratory tests used to distinguish PRA and ATN. Liver failure can be associated with paradoxically nearnormal values of both BUN (due to decline in urea production by the liver) and serum creatinine (due to muscle wasting), despite of a significant decline in renal function manifested by decreased Glomerular Filtration Rate (GFR). ${ }^{15}$

The causes of AKI can be classified as: prerenal (reduced renal perfusion or hypovolemia), intrinsic renal (glomerular or tubular) and postrenal. The normal reference range of BCR is around 8-15 and the most commonly used threshold to interpret increased BCR is $20 .{ }^{16}$ For BCR $>20$ it is attributed to prerenal type whereas with BCR $<20$ can be due to renal or postrenal type. ${ }^{17,18,19}$ This elevation in BCR is one of the indicators of decreased renal perfusion. BCR can also be very handy in diagnosing gastrointestinal bleeding in some patients who do not present with overt blood loss. $20-23$ Though now there is less evidence supporting BCR as a criterion to distinguish between these two conditions still we can use this as a reference when we do not have repeated blood values and GFR to diagnose a renal failure. The aim of the study was to find out the prevalence of renal impairment in the patients of liver cirrhosis with or without SBP.

\section{MATERIAL AND METHODS}

This was observational, prospective, single center study and was conducted at Department of Pharmacology, Maulana Azad medical college, Department of Gastroenterology and Department of Microbiology, Govind Ballabh Pant Institute of
Postgraduate Medical Education and Research, New Delhi. A sample size of convenience of 32 patients was taken. The study was carried out after receiving approval from Departmental Scientific Committee and the Institutional Ethics Committee.

Inclusion Criteria: 1) A patient of age above 18 and below 75 years of either sex was included 2) A diagnosed case of SBP or a patient with protein in ascitic fluid less than 1.5 $\mathrm{gm} / \mathrm{dl}$

Methods: Consecutive patients that were already diagnosed with cirrhosis by the clinicians and satisfied the inclusion criteria were enrolled after taking proper informed consent from the Gastroenterology ward and Intensive Care Unit. On hospitalization, the patients underwent the required basic and specific investigations and were given the standard of care as per the hospital protocol and clinical judgment of the clinicians. The demographic data was enquired from the patient or from the patient relatives and serum creatinine and urea values of all included patients were collected from the investigation chart of the patient. Our aim was to find out the prevalence of renal impairment of cirrhotic patients on admission hence we did not take the repeated blood values of patients during their stay in the hospital. Renal impairment was considered if the serum creatinine (0.7-1.2 $\mathrm{mg} / \mathrm{dl}$ for males and $0.5-0.9 \mathrm{mg} / \mathrm{dl}$ in females by Jaffe kinetic method) or urea ( $<50 \mathrm{mg} / \mathrm{dl}$ by Urease GLDH method) or both were above the reference range. We converted the plasma urea values into BUN values using the formula:

Blood urea nitrogen $\times 2.14=$ blood urea

The BUN values were further utilized to obtain the BCR which is given by formula:

\section{$\mathrm{BCR}=\mathrm{BUN}(\mathrm{mg} / \mathrm{dl}) /$ Creatinine $(\mathrm{mg} / \mathrm{dl})$}

We further a subgroup analysis and divided the patients on the basis of BCR criteria to with BCR $<20$ and BCR $>20$. To assess the variation of BCR values more thoroughly, they were further divided into eight subgroups according to BCR $(<10,10-15,16-20,21-25,26-30,31-35,36-40$ and $>40)$.

\section{Statistical analysis}

The data was entered in MS Excel and was analyzed using statistical software SPSS version 20. The demographic data was presented as Mean + Standard deviation. The groups were compared using student's unpaired t-test. Chi square test and Mann Whitney U Test were used to compare the data with non-normal distribution. A p value of $<0.05$ was considered significant.

\section{RESULTS}

A total of 34 patients were enrolled in the study who satisfied the inclusion criteria. They were further divided into two groups. 22 patients with diagnosed SBP were assigned Group A (SBP) and 12 patients with low ascitic fluid protein were assigned Group B(LA). The demographic data and blood parameters of the patients are summarized in the table 1.

Table 1: Demographic variables and blood parameters of the patients

\begin{tabular}{|l|l|l|l|}
\hline & Group A & Group B & p value \\
\hline Age, Years(Mean \pm SD) & $51.86 \pm 10.16$ & $42.67 \pm 10.93$ & $\mathrm{p}=0.71$ \\
\hline Sex, M/F & $20 / 2$ & $12 / 0$ & \\
\hline Male, n(\%) & $90 \%$ & $100 \%$ & \\
\hline Serum Urea (mg/dL) & $78.95 \pm 34.8$ & $66.69 \pm 28.07$ & $\mathrm{p}=0.44$ \\
\hline Serum Creatnine (mg/dL) & $1.44 \pm 0.60$ & $1.35 \pm 0.32$ & $\mathrm{p}=0.75$ \\
\hline
\end{tabular}


All the parameters were equally matched as shown in the table 1.

Both the groups were analyzed for assessment of renal impairment on the basis of serum urea and creatinine values and it was observed that there was no significant difference $(p=0.24)$ between the two groups. Results are summarized in the table 2 .

Table 2: Assessment of renal impairment among the patients of liver cirrhosis

\begin{tabular}{|l|l|l|l|}
\hline & Total Patients & Patients with Renal Impairment & Percentage of Patients with Renal Impairment \\
\hline Group A (SBP) & 22 & 17 & $77.27 \%$ \\
\hline Group B (LA) & 12 & 7 & $58.33 \%$ \\
\hline Total & 34 & 24 & $70.58 \%$ \\
\hline
\end{tabular}

SBP= Spontaneous Bacterial Peritonitis, LA= low Ascitic fluid albumin

The plasma urea was converted into BUN (mg/dl) for calculation of BCR in both the groups. Both the groups were further analyzed on the basis of BCR and further subdivided into $B C R<20$ and $B C R>20$. Our study showed that majority of the patients were in the BCR $>20$ group which denotes a renal impairment of prerenal type. The results are summarized in table 3 .

Table 3: Table summarizing the patients on the basis of BUN:Creatinine Ratio (BCR)

\begin{tabular}{|l|l|l|}
\hline & BCR<20 & BCR>20 \\
\hline Group A & 7 & 15 \\
\hline Group B & 7 & 5 \\
\hline Total patients & 14 & 20 \\
\hline
\end{tabular}

On further subdividing all the patients of both group on the basis of variable BCR $(<10,10-15,16-20,21-25,26-30,31-$ $35,36-40$ and $>40$ ) we found majority of the patients (12) in the $\mathrm{BCR}=16-20$ range. Seven patients in 21-25 range, six in
26-30 range, three in 10-15 range, three in $>40$, two in 36-40 and one in 31-35 range. The results are summarized in figure no. 1

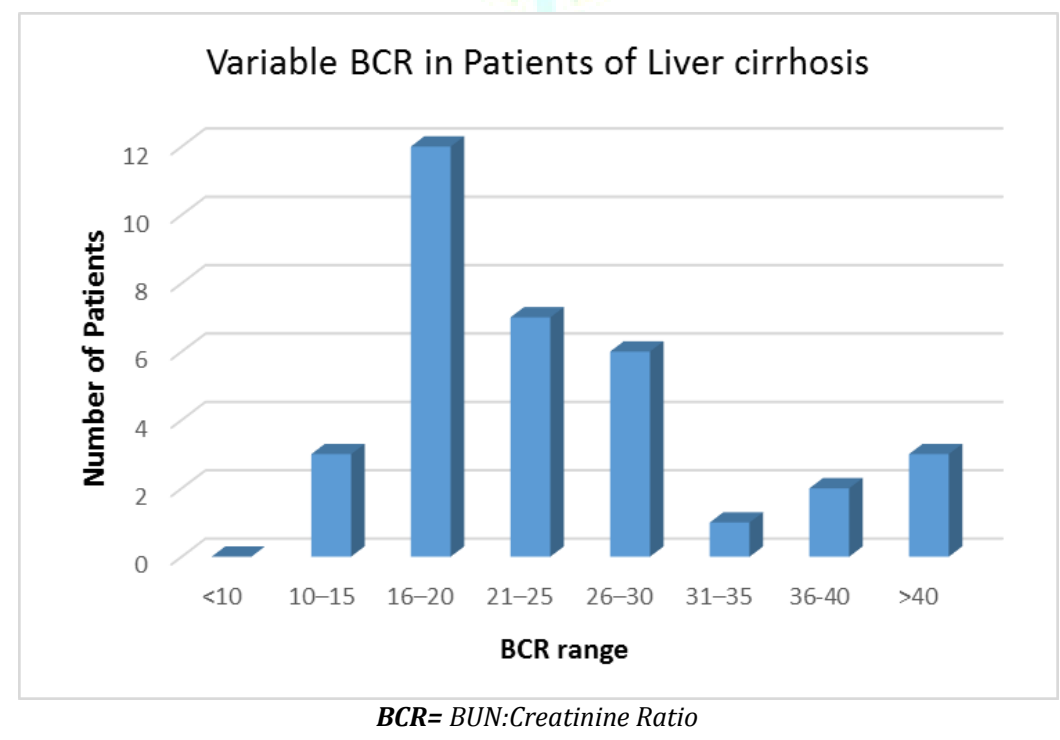

Figure 1: Figure summarizing the variability and distribution of BCR among patients

\section{DISCUSSION}

Our study was conducted on 34 patients of liver cirrhosis with ascites having SBP or low ascitic fluid albumin to determine the prevalence of renal impairment in these patients. The demographic and blood parameters were matched. In the present study almost $70.58 \%$ of the patients had renal impairment which was denoted by elevated serum creatinine and/or urea values. Previous studies have shown that AKI has an estimated prevalence of about $20-50 \%$ among hospitalized patients with cirrhosis. 4,24-27 The burden of renal impairment in patients with SBP was $77.27 \%$ which was more as compared to the patients without SBP (58.33\%) which can be because of more deteriorating condition of the patient with SBP. Previous studies have shown about 33$34 \%$ of patients with SBP are prone to develop renal failure. ${ }^{25,29}$ In our study we found an increased prevalence of renal impairment based on deranged renal parameters but could not ascertain it as a renal failure.

On further classifying the patients on the basis of BCR, majority of the patients were in the $\mathrm{BCR}>20$ group which shows they had a renal impairment of prerenal type which could be explained by the fact that there is effective decrease in blood volume in patients with cirrhosis and ascites leading to compromised renal perfusion. ${ }^{30,31}$ On subdividing the patients on the basis of BCR we found majority of the patients in the $\mathrm{BCR}=16-20$ group which mostly denotes an 
intrarenal pathology leading to impaired renal function. 17,18,19 However we also found 3 patients who had BCR $>40$ which indicates towards a concealed or obvious gastrointestinal hemorrhage somewhere in the gut which is quite common in these patients of cirrhosis with ascites. ${ }^{20-23}$

Though our study results indicates more towards prerenal type of injury, but we could not assure the fact as BCR criteria is not a precise criterion to diagnose renal injury. There are other superior criteria like RIFLE and AKIN which are more reliable as compared to BCR. Small sample size is another limitation in our study. However, our study gives an idea about the common occurrence of renal impairment in the patients of liver cirrhosis and ascites.

Funding: No funding sources

\section{Conflict of Interest: None declared}

\section{REFERENCES}

1. Cirrhosis. Mayo Clinic. Accessed on 23 Jan 2019 from URL: https://www.mayoclinic.org/diseases-

conditions/cirrhosis/symptoms-causes/syc-20351487

2. Garcia-Tsao G. Current management of the complications of cirrhosis and portal hypertension: variceal hemorrhage, ascites, and spontaneous bacterial peritonitis. Gastroenterology. 2001; 120:726-48.

3. Nusrat S, Khan MS, Fazili J, Madhoun MF. Cirrhosis and its complications: evidence based treatment. World J Gastroenterol. 2014; 20(18):5442-60.

4. Garcia-Tsao G, Parikh CR, Viola A: Acute kidney injury in cirrhosis. Hepatology 2008; 48:2064-77.

5. Ginès $\mathrm{P}$, Cárdenas $\mathrm{A}$, Arroyo $\mathrm{V}$, Rodés J: Management of cirrhosis and ascites. N Engl J Med 2004; 350:1646-54.

6. Angeli P, Gines P, Wong F, et al: Diagnosis and management of acute kidney injury in patients with cirrhosis: revised consensus recommendations of the International Club of Ascites. Gut 2015; 64:531-7.

7. Runyon BA. Patients with deficient ascitic fluid opsonic activity are predisposed to spontaneous bacterial peritonitis. Hepatology. 1988; 8:632-5.

8. Dutta S, Chawla S, Srivastava S, Loomba P. Spontaneous bacterial peritonitis: a review. International Journal of Current Medical and Pharmaceutical Research Nov 2018; 4(11A):38726.

9. Lopes JA, Jorge S. The RIFLE and AKIN classifications for acute kidney injury: a critical and comprehensive review.Clin Kidney J 2013; 6:8-14.

10. Angeli P, Gines P, Wong F, et al: Diagnosis and management of acute kidney injury in patients with cirrhosis: revised consensus recommendations of the International Club of Ascites. Gut 2015; 64:531-7.

11. Khwaja A: KDIGO clinical practice guidelines for acute kidney injury. Nephron Clin Pract 2012; 120:179-84.

12. Appenrodt B, Lammert F. Renal Failure in Patients with Liver Cirrhosis: Novel Classifications, Biomarkers, Treatment. Visc Med. 2018; 34(4):246-52.
13. Liañ F, Pascual J. Madrid Acute Renal Failure Study Group.Epidemiology of acute renal failure: a prospective, multicenter,community-based study. Kidney Int 1996; 50:8118

14. Esson ML, Schrier RW. Diagnosis and treatment of acute tubular necrosis. Ann Intern Med 2002; 137:744-52

15. Sherman DS, Fish DN, Teitelbaum I. Assessing renal function in cirrhotic patients: problems and pitfalls. Am J Kidney Dis. 2003; 41(2):269-78.

16. Baum $\mathrm{N}$ et al. Blood urea nitrogen and serum creatinine. Urology 1975; 5(5):583-88.

17. Lyman JL. Blood urea nitrogen and creatinine. Emerg Med Clin North Am 1986; 4(2):223-33.

18. Agrawal M et al. Acute renal failure. Am Fam Physician 2000; 61(7):2077-88.

19. Stetka B, Ostermann M. Can You Predict AKI in the Critically Ill With BCR? Accessed on 23 Jan from URL: https://www.medscape.com/viewarticle/774468

20. Snook JA et al. Value of a simple biochemical ratio in distinguishing upper and lower sites of gastrointestinal haemorrhage. Lancet 1986; 1(8489):1064-65.

21. Felber $\mathrm{S}$ et al. The $\mathrm{BUN} /$ creatinine ratio in localizing gastrointestinal bleeding in pediatric patients. J Pediatr Gestroenterol Nutr 1988; 7(5):685-87.

22. Olsen LH et al. Stools containing altered blood-plasma urea: creatinine ratio as a simple test for the source of bleeding. Br J Surg 1991; 78(1):71-73.

23. Ernst AA et al. Usefulness of the blood urea nitrogen/creatinine ratio in gastrointestinal bleeding. Am J Emerg Med1999; 17(1):70-72.

24. Piano S, Rosi S, Maresio G. et al. Evaluation of the Acute Kidney Injury Network criteria in hospitalized patients with cirrhosis and ascites. J Hepatol 2013; 59:482-9.

25. Follo A, Llovet J, Navasa M. et al. Renal impairment after spontaneous bacterial peritonitis in cirrhosis: incidence, clinical course, predictive factors and prognosis. Hepatology 1994; 20:1495-501.

26. Hampel H, Bynum GD, Zamora E, El-Serag HB. Risk factors for the development of renal dysfunction in hospitalized patients with cirrhosis. Am J Gastroenterol 2001; 96:2206-10.

27. Bucsics T, Krones E. Renal dysfunction in cirrhosis: acute kidney injury and the hepatorenal syndrome. Gastroenterol Rep (Oxf). 2017; 5(2):127-37.

28. Carvalho GC, Regis Cde A, Kalil JR, Cerqueira LA, Barbosa DS, Motta MP, da Silva Nery M, Pires Soares MA, Zollinger CC, Bittencourt PL. Causes of renal failure in patients with decompensated cirrhosis and its impact in hospital mortality. Ann Hepatol. 2012; 11:90-5.

29. Fasolato S, Angeli P, Dallagnese L, Maresio G, Zola E, Mazza E et al. Renal Failure and Bacterial Infections in Patients with Cirrhosis: Epidemiology and Clinical Features. American Association for the Study of Liver Diseases. Accessed on 28 Jan 2019. from URL:

https://aasldpubs.onlinelibrary.wiley.com/doi/pdf/10.1002/hep.21443

30. Ginès $P$, Schrier RW. Renal failure in cirrhosis. N Engl J Med. 2009; 361:1279-90.

31. Russ KB, Stevens TM, Singal AK. Acute Kidney Injury in Patients with Cirrhosis. J Clin Transl Hepatol. 2015; 3(3):195-204. 